\title{
Technologies used to minimize oncological pain in children and adolescents: a literature review
}

\begin{abstract}
Objective: To identify the technologies available for the management of cancer pain in the literature.

Method: This is an integrative literature review carried out in the databases SCOPUS, PubMed/MEDLINE, LILACS e CINAHL. Initially, there were 81 articles selected, and the sample consisted of nine articles. The keywords used were child oncologic pain, protocols, Technology and guidelines. The AND or OR Boolean operator was used. The search was conducted in July and August 2017.
\end{abstract}

Results: The articles included in this review aimed at identifying technologies that could be used in children and adolescents with cancer pain. It was found that the technologies used were protocols, guidelines, leaflets, programs, and applications.

Conclusion: Technologies are strategies that help promote the relief and control of cancer pain, associated with pharmacological and non-pharmacological strategies.

Keywords: technology, child, pain, cancer

\author{
Volume 4 Issue 3 - 2017 \\ Silvania Moreira de Abreu Façanha, Edna \\ Maria Camelo Chaves, Rhanna Emanuela \\ Fontele Lima de Carvalho \\ Ceara State University, Brazil
}

Correspondence: Edna Maria Camelo Chaves, Ceara State University, Brazil, Tel + 5585 3101-9606, Email ednacam3@gmail.com

Received:September 30, 2017 | Published: December 19, 2017

\section{Introduction}

The pain suffered by the child in oncological treatment goes beyond the pain of cancer. It can be related to other factors of physical, emotional, social and spiritual origin, being conceptualized with total pain. ${ }^{1}$ This is defined as an unpleasant sensory and emotional experience that may be related to actual or potential tissue injury. ${ }^{2}$ It is known that chemotherapy treatment requires invasive procedures such as punctures, being very painful for children.

Cancer pain goes beyond the physical dimension, and it has individual and collective meaning, influenced by the individual's life experience, able to change family dynamics and compromise daily activities. This painful experience is also subjective and deserves special attention by all the staff involved in the care of the child in cancer treatment, in particular, the nursing that provides care frequently. Pain control in children with cancer is a challenge because of the difficulty that the nursing team has in choosing the pain measurement scale, especially for children 0 to 2 years old. ${ }^{3}$

Pain assessment in children needs a differentiated view that values their description, and the aspects of cognitive and linguistic development are fundamental for the interpretation of the painful experience. ${ }^{4}$ Health technologies are produced to optimize and standardize care, aiming to improve care, with the objective of evaluating, quantifying, and directing care. ${ }^{5}$ In the treatment of pain in children, strategies that can favor the relief and control of pain one must be thought. The aim of this study was to identify the available technologies for the management of cancer pain in the literature.

\section{Method}

It is a qualitative bibliographical research carried out by an integrative review of the literature, which is a research method that consists of the construction of a broad analysis of publications and contributes to discussions about methods and research results, as well as reflections on the performance of future studies. ${ }^{6}$
The following guiding question was established for the development of the study: what technologies have produced that aim to promote the relief of cancer pain in children? The search was performed in pairs, independently and concomitantly. The collection period was from July to August 2017, through online access in databases in the context of health: SCOPUS, PubMed/MEDLINE, LILACS, AND CINAHL. Dor oncológica [oncology pain]; criança [children]; protocols [protocols]; Tecnologia [Technology]; diretrizes [guidelines]. The Boolean operators AND or OR were used. Initially, 81 articles were selected, and only 9 were chosen.

The criteria established were: all articles published with technologies available in full in journals indexed in electronic databases, addressing technologies that promote pain relief. The exclusion criteria were theses and editorials. Data were organized into categories. Only 9 articles answered the study question

\section{Results and discussion}

From the analysis of the articles emerged two thematic categories, nursing care in oncologic pain and Assistive technologies to promote the relief of cancer pain.

\section{Nursing care in cancer pain}

Nursing care identified in the articles was pain assessment, ${ }^{7,8}$ administration of pharmacological and non-pharmacological

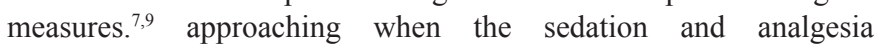
were initiated, ${ }^{9}$ and monitoring of children on sedation. ${ }^{10}$ Safe administration of drugs is a challenge for nurses who are in care, as it is known that these drugs produce many side effects. Nursing in health services is directly involved with drug administration and needs to have an understanding of the whole process. The guidance and training of parents, ${ }^{11}$ children and adolescents regarding the use of technologies ${ }^{11,12}$ is another important aspect, since cancer pain must be treated with all available resources. 


\section{Assistive technology for the promotion of cancer pain relief}

Three articles addressed pain relief with pharmacological measures. Assistive technologies have been used as a strategy to minimize the total pain experienced by children with cancer. Pain management training was conducted through lectures, feedback and active participation, resulting in improved quality of pain management. ${ }^{7}$ Based on the perceptions and experience of the medical and nursing staff for the use of the protocol, dealing with the adequate use of analgesia and sedation, the team favored the protocol and considered its effective use. $^{8}$ The third article deals with sedation during painful procedures and resulting in decreased suffering during procedures, less physical restraint and amnesia reporting during procedures. ${ }^{10}$ The distraction of the child was approached in four articles, the technologies were a therapeutic toy, ${ }^{8}$ virtual reality, ${ }^{13}$ drawing on distraction techniques ${ }^{11}$ and a tablet program. ${ }^{14}$ Three of the technologies were tested during painful procedures. All the technologies were pain-relieved.

The massage emerged as a technology and proved to be effective in reducing pain interference on the floor, contributing to relief and reducing interference in the child's activities, despite doubts about the effectiveness of this message protocol as it was evaluated in a small sample. However, its use was recommended for improving well-being and quality of life. ${ }^{15}$ The use of the application was tested by adolescents, resulting in an improvement in pain management. ${ }^{12}$ Aiming at the control of cancer pain, these technologies appear as important strategies to promote pain control and pain relief.

\section{Conclusion}

We can conclude that the technologies suggested have shown an effect on the control and relief of oncological pain in children and adolescents and pharmacological and non-pharmacological measures complement each other so pain can be minimized.

\section{Acknowledgements}

None.

\section{Conflict of interest}

The author declares no conflicts of interest.

\section{References}

1. Saunders C. Care of patients suffering from terminal illness at St Joseph's Hospice, Hackney, London. Nursing Mirror. 1964. p. 7-10
2. IASP- International association for study of pain. Subcommittee on taxonomy. Classification of cronic pain: Descriptions of chronic pain syndromes and definitions of pain terms. Pain. 1986;(Suppl 3).

3. Chotolli MR, Luize PB. Non-pharmacological approaches to control pediatric cancer pain: nursing team view. Rev Dor. 2015;16(2):109-113.

4. Studart-Pereira LM, Cordeiro AA de A, Queiroga BA de M. Descritores de dor presentes nas narrativas de crianças em tratamento oncológico. Estud Psicol. 2015;20(4):241-250.

5. Brasil Ministério da Saúde. Secretaria de Ciência Te IED de Ce T. Agenda nacional de prioridades de pesquisa em saúde; 201568 p.

6. Mendes KDS, Silveira RC de CP, Galvão CM. Evidencias en la sintegrativa: método de pesquisa para a. Texto Context-Enferm. 2008;17(4):758-764.

7. Zernikow B, Hasan C, Hechler T, et al. Stop the pain! A nation-wide quality improvement programme in paediatric oncology pain control. Eur J Pain. 2008;12(7):819-833.

8. Batista M, Sabino DM, Almeida FDA. Therapeutic play as a pain relief strategy for children with cancer. 2006;4(3):196-202.

9. Bidet G, Daoust L, Duval M, et al. An order protocol for respiratory distress/acute pain crisis in pediatric palliative care patients: medical and nursing staff perceptions. J Palliat Med. 2016;19(3):306-313.

10. Macpherson CF, Lundblad LA. Conscious sedation of pediatric oncology patients for painful procedures: development and implementation of a clinical practice protocol. J Pediatr Oncol Nurs. 1997;14(1):33-34.

11. Christensen J, Fatchett D. Use of distraction and relaxation in pediatric oncology patients during invasive procedures. J Pediatr Oncol Nurs. 2002;19(4):127-132.

12. Jibb LA, Stevens BJ, Nathan PC, et al. Implementation and preliminary effectiveness of a real-time pain management smartphone app for adolescents with cancer: A multicenter pilot clinical study. Pediatr Blood Cancer. 2017;64(10):1-9.

13. Gershon J, Zimand E, Pickering M, et al. A pilot and feasibility study of virtual reality as a distraction for children with cancer. J Am Acad Child Adolesc Psychiatry. 2004;43(10):1243-1249.

14. Fortier MA, Chung WW, Martinez A, et al. Pain buddy: A novel use of m-health in the management of children's cancer pain. Comput Biol Med. 2016;76:202-214.

15. Batalha LM, Mota AA. Massage in children with cancer: Effectiveness of a protocol. J Pediatr (Rio J). 2013;89(6):595-600. 